\title{
Distribution of Human Papillomaviruses in Women
}

\author{
Sara Shirly George ${ }^{a} \quad$ Usha K. Luthra ${ }^{a}$ Mariam Chishti ${ }^{b}$ \\ Azza Abdul Aziz Shaheen ${ }^{c}$ Josely George ${ }^{a}$ \\ aDepartment of Pathology, Faculty of Medicine, Kuwait University, ${ }^{b}$ Farwaniya Hospital, and \\ cMubarak Al-Kabeer Hospital, Kuwait
}

\section{Key Words}

Hybrid capture assay $\cdot$ Human papilloma virus. Squamous intra-epithelial lesions

\begin{abstract}
Objectives: To study the distribution of human papillomviruses (HPV) in women in Kuwait using hybrid capture assay and their correlation with the severity of cervical lesions based on cytological diagnosis and to establish the relationship if any between the quantity of the viral load and the degree of severity of cervical lesions. Methods: Study sample included 181 women in the age range of 20-68 years, attending the Out-Patient Department of Gynaecology of the Al-Farwaniya Hospital and six polyclinics in Kuwait during the years 1997-1998. Cervical smears were interpreted according to the modified Bethesda System. HPV DNA was detected using a chemiluminescent-based Digene hybrid capture assay. Results: Of the 181 wom-
\end{abstract}

\begin{tabular}{ll}
\hline KARGER & ( 2000 S. Karger AG, Basel \\
Fax +4161306 1234 & $1011-7571 / 00 / 0092-0106 \$ 17.50 / 0$ \\
$\begin{array}{l}\text { E-Mail karger@karger.ch } \\
\text { www.karger.com }\end{array}$ & $\begin{array}{l}\text { Accessible online at: } \\
\text { www.karger.com/journals/mpp }\end{array}$
\end{tabular}

en studied, the cytodiagnosis was as follows: normal and inflammation 139 (76.8\%), atypical squamous cells of undetermined significance (ASCUS) and atypical glandular cells of undetermined significance (AGUS) 26 (14.4\%) and squamous intra-epithelial lesion (SIL) 16 (8.8\%). High-risk HPV DNA had a very low prevalence in women with normal and inflammation cytology, i.e. $1.4 \%$ in contrast to women with SIL lesions which had a positivity of $68.8 \%$. ASCUS and AGUS group had 7.7\% high-risk HPV DNA positivity. The quantity of viral load was directly related to the increase in the severity of the lesions. Conclusion: High-risk HPV DNA was detected in a significantly higher proportion of women with SIL lesions as compared to those with normal cytology ( $p<0.0001$ ). Furthermore, the viral load of high-risk HPV DNA was directly related to the severity of the cervical lesions, relative light unit ratios being $>20$ in the majority of SIL lesions.

$$
\text { Copyright (C) } 2000 \text { S. Karger AG, Basel }
$$

\footnotetext{
Dr. Sara Shirly George, Scientific Assistant

Department of Pathology, Faculty of Medicine, Kuwait University PO Box 24923, 13110 Safat (Kuwait)

Tel. +965 5312300 , ext. 6293, Fax +965 5338905

E-Mailsara@hsc.kuniv.edu.kw
} 


\section{Introduction}

Cervical cancer is the third commonest cancer among Kuwaiti women with an incidence rate of 7.6 per 100,000 population (cancers of the breast and lung being the first and second) [1]. Epidemiological and experimental evidence suggest that human papillomavirus (HPV) is an important infectious agent associated with cervical cancer [2]. No published data are available on the prevalence or even distribution of HPV in women in $\mathrm{Ku}-$ wait.

A recent diagnostic technique, the liquidbased cytology, ThinPrep Pap preparation has been evolved to replace the conventional Pap smear to provide more clarity, uniformity and reproducibility to the smear [3, 4]. An added option exists of carrying out HPV DNA testing by the Digene hybrid capture assay (HCA) on the residual cellular material suspended in Preservcyt solution of ThinPrep samples after smear preparation. This would result in substantial cost reduction and reduce additional clinic visits to confirm Pap smear abnormality or to obtain a separate specimen for the HPV test [5, 6].

The distribution of HPV in women in Kuwait using HCA and their correlation with the severity of cervical lesions based on cytological diagnosis were investigated in this study. The relationship if any between the quantity of the viral load and the degree of severity of lesions was also examined.

\section{Material and Methods}

The study sample consisted of 181 women (20-68 years), attending the Gynaecological Department of the Al-Farwaniya Hospital and six polyclinics in $\mathrm{Ku}-$ wait. Of these women, 35 were referred for Digene HCA testing based on cytological abnormalities revealed on previous Pap smears or on clinical suspicion. Cervical scrapes from these women were collected in
Digene specimen vials containing $1 \mathrm{ml}$ Digene transport medium with an endocervical swab. The remaining 146 women had samples collected in Preservcyt solution for ThinPrep smear from which the material was used according to the protocol supplied by Digene. It was mandatory that a conventional smear be taken from all the women. Cervical smears were interpreted according to the modified Bethesda System in the cytology laboratory of the Al-Mubarak Al-Kabeer Hospital and the Faculty of Medicine, Kuwait. ThinPrep diagnosis was also made wherever ThinPrep samples were obtained and the higher of the two diagnoses, i.e. between conventional Pap smear and ThinPrep smear, was taken in 19 cases where there was discrepancy.

\section{Digene HPV Testing}

HPV DNA was determined by the hybrid capture HPV DNA assay, according to the manufacturer's instructions provided along with the kit. Briefly, denatured DNA sample was hybridised in solution with two different sets of single-stranded RNA probe cocktails for the 5 low-risk $6,11,42,43,44$ types and 9 mediumand high-risk 16, 18, 31, 33, 35, 45, 51, 52, 56 types, respectively. These hybrids were captured by immobilised antibodies specific for RNA-DNA hybrids that are coated on a plastic tube. Captured RNA-DNA hybrids are then detected in a chemiluminescent reaction with an alkaline-phosphatase-conjugated antibody directed against RNA-DNA hybrids. The reaction was quantified as relative light units (RLU) measured by a luminometer. A ratio of specimen RLU per positive control RLU was calculated and a reading was termed positive if a ratio $\geq 1.0$ was calculated.

Samples which were reported normal and inflammation by cytodiagnosis were tested mainly by the combined probe cocktail method whereby the probes were mixed together and samples tested. If any sample was positive in this screening assay, it was then tested by the two-probe method whereby it was possible to classify into high- and low-risk types. All samples with an abnormal cytological diagnosis were subjected to the two-probe method.

The association between cytodiagnosis and HPV test results in terms of high-risk HPV DNA positivity and viral load was analysed in $2 \times 2$ contingency tables by Fisher's exact test for $p$ value. 


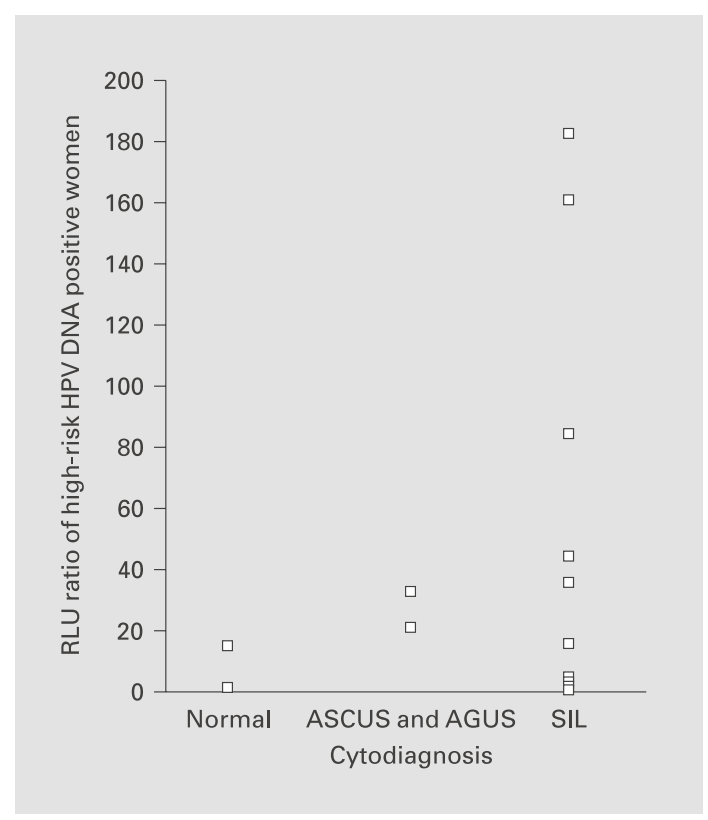

Fig. 1. RLU ratio of high-risk HPV DNA-positive women by cytodiagnosis.

\section{Results}

The 181 cases which were studied by Digene assay were comprised of 60 samples with normal cytology, 79 inflammatory, 24 of atypical squamous cells of undetermined significance (ASCUS), 2 of atypical glandular cells of undetermined significance (AGUS), 13 low-grade squamous intra-epithelial lesions (SIL) and 3 high-grade SIL. In subsequent analyses, cases with normal and inflammatory cytology were grouped together as normal and so also were the cases of ASCUS and AGUS. As indicated, there were only 3 cases of high-grade SIL, hence for analysis, all cases of SIL, low-grade and high-grade, were grouped together. Thus, the cytodiagnosis was as follows: normal 139 (76.8\%); ASCUS and AGUS 26 (14.4\%); SIL 16 (8.8\%).
Table 1. Distribution of low-risk and high-risk HPV by cytodiagnosis $(n=181)$

\begin{tabular}{lrrrr}
\hline Cytodiagnosis & \multicolumn{2}{c}{ HPV DNA positivity } & Total \\
\cline { 2 - 3 } & \multicolumn{3}{c}{$\begin{array}{c}\text { negative } \\
\text { pow-risk } \\
\text { positive }\end{array}$} & $\begin{array}{l}\text { high-risk } \\
\text { positive }\end{array}$ \\
\hline Normal & 137 & - & 2 & 139 \\
ASCUS and & & & & \\
$\quad$ AGUS & 22 & 2 & 2 & 26 \\
SIL & 4 & 1 & 11 & 16 \\
\hline
\end{tabular}

The overall HPV DNA positivity was only $2 / 139(1.4 \%)$ in the normal group, 4/26 $(15.4 \%)$ in the atypical group, i.e., ASCUS and AGUS group, and 12/16 (75.0\%) in the SIL category. The 2 positive cases in the normal population belonged to the high-risk category. Of the 4 positive cases in the ASCUS and AGUS group, 2 were high-risk types. All the positive cases in the SIL category except 1 belonged to the high-risk group. One case showed double positivity being positive for both high- and low-risk groups (table 1). Thus the high-risk HPV DNA positivity was found to be $2 / 139(1.4 \%)$ of the normal group, $2 / 26$ (7.7\%) in the ASCUS and AGUS group and $11 / 16(68.8 \%)$ in the SIL group. The proportion of high-risk HPV was significantly higher $(p<0.0001)$ in the SIL group as compared to the normal group, as also between the SIL and atypical category $(\mathrm{p}<0.0001)$.

Quantification of HPV DNA by Digene assay revealed that the viral load was negligible in the normal population with RLU ratios ranging between 1-4.99 and 15-19.99. However, there was a trend in the increase of HPV load corresponding to the increase in the severity of cervical lesions, with 2 ASCUS and AGUS cases and 5 SIL cases having RLU ratios $>20$ (table 2). Furthermore, the distribution of RLU ratios of high-risk HPV-posi- 
Table 2. Distribution of RLU ratios in HPV-positive women by cytodiagnosis $(\mathrm{n}=181)$

\begin{tabular}{lllllll}
\hline Cytodiagnosis & \multicolumn{3}{l}{ RLU ratios } & & Total \\
\cline { 2 - 6 } & negative & $1-4.99$ & $5-14.99$ & $15-19.99$ & 20 & \\
\hline Normal & 137 & 1 & - & 1 & - & 139 \\
ASCUS and AGUS & 22 & 1 & 1 & - & 2 & 26 \\
SIL & 4 & 4 & 2 & 1 & 5 & 16 \\
\hline
\end{tabular}

tive cases as shown in figure 1 also illustrates the same trend. The values in the normal group were restricted to the lower end of the scale whereas the values of the ASCUS and AGUS group and the SIL category were found over a much wider range as high as 180 . Significant difference was found in the high-risk HPV cases with RLU ratios $>20$ between the SIL category and the normal group ( $\mathrm{p}<$ 0.0001).

\section{Discussion}

Certain subsets of HPV have been regarded as a major risk factor for cervical cancer. Though the Papanicolaou test can reveal various cytological abnormalities related to HPV, it is unable to distinguish between the low-risk and high-risk types. Identification of these groups may be of value in the clinical management of patients as some HPV types, like 6 and 11, are largely incriminated with benign lesions, while others such as HPV 16 and 18 are associated with high-grade lesions that may even eventually progress to malignancy $[7,8]$.

Molecular techniques like in situ hybridisation, polymerase chain reaction (PCR) and Digene HCA are increasingly being employed to help identify the various types of HPV DNA $[9,10]$. PCR is a highly sensitive meth- od for generating large amount of DNA from minute amounts as little as 1-10 genomes of target DNA. However, its exquisite sensitivity may be its greatest drawback thus questioning the clinical significance of PCR-positives. This coupled with other disadvantages like the need for DNA extraction, and extreme contamination risk makes it less feasible for routine use. In situ hybridisation has the advantages of revealing the location of specific HPV-infected cells or tissue regions on glass slides, the minimum detection limit being 5,000 genomes. However, it is time-consuming and laborious with subjective evaluation of the intensity of positive signals.

HCA is a relatively new technique using non-radioactive hybridisation assay for the detection of HPV DNA without the need for the extraction of DNA. The test reports the presence or absence of HPV and whether low or intermediate and high oncogenic risk virus types are present. Quantification of HPV DNA is possible which helps us to make an objective assessment. This is a ray of hope in the field of cervical cytology where subjectivity plays an important role in any decisionmaking process by the cytopathologist.

The combination of ThinPrep preparation along with HCA testing on the same sample further reduces the costs and saves additional follow-up visits to the clinic for HPV testing. Ferris et al. [11] advocate the use of a recently 
introduced second generation test, the hybrid capture microplate test, which affords 50 times more analytical sensitivity, takes less time and tests four more high-risk HPV types $(39,58,59$ and 68$)$ in addition to fourteen tested by HCA.

HPV DNA was seen to have a low frequency in women with normal cytology $(1.4 \%)$, whereas the percentage of HPV DNA detected progressively increased from $15.4 \%$ in equivocal ASCUS and AGUS lesions to $75.0 \%$ in SIL cases in our study.

However, the low percentage of HPV positivity detected in cases with normal cytology is a cause of concern. This may be because there is not sufficient viral DNA in the specimen to befit such cases as HCA-positive. Of the 139 cases comprising normal population, 127 cases were tested for HPV DNA from the residual fluid of Preservcyt solution after preparation of ThinPrep smear. The two high-risk HPV DNA-positive cases detected in the normal population had samples collected in Digene specimen vials. In ThinPrep preparation, split-sample method was followed in which the sample collected was first used for conventional smear preparation and the remaining sample was rinsed in Preservcyt solution. Sherman et al. [12] have also remarked that the preparation of $\mathrm{CP}$ smears before the ThinPrep slides might have produced a reduction in the number of cells available for HPV DNA testing, resulting in loss of sensitivity of the HPV test.

Suboptimal sampling by the endocervical cotton swab and the fact that HCA requires a minimum threshold of 50,000 copies of viral genome for positive result may also be other reasons ascribed for this $[5,13-15]$. The device of collection, the cytobrush, is considered superior to the endocervical swab provided with the HCA [10]. Lorincz [14] has highlighted the importance of specimen adequacy to avoid false negatives, and the use of brush devices rather than dacron swabs in cutting through mucus or other material to access HPV-infected cells. But, from a clinical point of view, cases with few copies of viral DNA may not have much significance [8, 9]. Furthermore, the high rate of detection of HPV DNA in SIL cases more than offsets this disadvantage.

High-risk HPV DNA was detected in 1.4\% of women with normal cytology with a low viral load. Various authors have reported figures ranging from 5.6 to $20 \%$ high-risk HPV in women with normal smears [10,12]. Women with normal cytology harbouring high-risk HPV types are considered to be more at risk of developing high-grade SIL in contrast to women without high-risk HPV [16]. Many HPV infections regress spontaneously. In contrast, HPV persistence engenders the risk for malignant progression [17]. Hence, the importance of detecting high-risk HPV DNA in cytologically normal smears cannot be sidelined. Diligent follow-up of these cases to trace the development of significant lesions, if any, is also required.

In the present study, 2 of the 26 cases of ASCUS and AGUS were associated with high-risk HPV. This number is too small to make any comparison. However, both the cases had a higher viral load between 20 and 40 RLU ratios (fig. 1). The ASCUS and AGUS group is a heterogeneous basket of assorted borderline cytologic changes with variable biological behaviour that do not fulfill the criteria for inclusion as low- or highgrade SIL. Detection of high-risk HPV DNA in this group may help to identify the small subset of women with ASCUS and AGUS which may have the potential to develop into higher grades of cervical lesions. Distinguishing between the low- and high-risk HPV types in women with equivocal diagnoses also helps in the clinical management of these women and cuts down the health care costs consider- 
ably by reducing the number of colposcopies $[18,19]$.

As expected, SIL category recorded the highest high-risk HPV DNA positivity $(68.8 \%, 11 / 16)$. This is in line with the findings of other authors who have reported values ranging from 70 to $78 \%$ for high-grade SIL and $41-62 \%$ for low-grade SIL. The viral load was also seen to correlate directly with the severity of the cervical lesions with the majority of high-risk HPV DNA found at RLU ratios $>20$ in SIL lesions (fig. 1) as compared to the other cytological groups, where HPVpositive cases had a predominantly lower viral load ranging from RLU ratios 1 to $<20$ irrespective of whether they were low- or highrisk types (table 2). Similar observations have been reported by other workers $[15,20,21]$. In contrast, a few studies have however not observed this correlation of the high levels of high-risk HPV DNA and the severity of the cervical lesions [13, 22].
In conclusion, HCA is a relatively easy, non-radioactive method for the detection of HPV DNA. This study demonstrated correlation of HPV DNA detection with the cytodiagnosis of cervical smears according to the Bethesda System. Quantification of HPV DNA and its ability to type HPV DNA is an added advantage. High-risk HPV DNA was detected in a significantly higher proportion of women with SIL lesions as compared to those with normal cytology $(\mathrm{p}<0.0001)$. Furthermore, the viral load of high-risk HPV DNA was directly related to the severity of the cervical lesions, RLU ratios being $>20$ in majority of SIL lesions.

\section{Acknowledgements}

The authors gratefully acknowledge the assistance rendered in statistical analysis by Dr. T.N. Sugathan, Associate Professor, Department of Community Medicine, Faculty of Medicine, Kuwait University.

\section{References}

1 Parkin DM, Whelan SL, Ferlay J, Raymond L, Young J: Cancer incidence in five continents. IARC Sci Publ No 143. Lyon, 1997, vol 7, Kuwait data, Anjum Memom, Ali N. Al-Muhanna.

2 Herrington CS: HPV and cervical neoplasia. I. Classification, virology, pathology and epidemiology. J Clin Pathol 1994;47:1066-1072.

3 Linder J, Zahniser D: The ThinPrep Pap test: A review of clinical studies. Acta Cytol 1997;41:30-38.

4 Papillo JL, Zarka MA, St John TL: Evaluation of the ThinPrep Pap test in clinical practice: A seven month, 16,314-case experience in Northern Vermont. Acta Cytol 1998;42:203208.

5 Ferenczy A, Franco E, Arseneau J, Wright TC, Richart RM: Diagnostic performance of hybrid capture human papillomavirus deoxyribonu- cleic acid assay combined with liquid-based cytologic study. Am J Obstet Gynecol 1996;175:651-656.

6 Lorincz A: Human papillomavirus testing: Pro. Pathol Case Rev 1997; 2:43-48.

7 Wieland U, Pfister H: Molecular diagnosis of persistent human papilloma virus infections. Intervirology 1996;39:145-157.

8 Trofatter KF: Diagnosis of human papillomavirus genital tract infection. Am J Med 1997; 102:21-27.

9 Lorincz AT: Molecular methods for the detection of human papilloma infection. Obstet Gynecol Clin North 1996;23:707-729.

10 Clavel C, Bory J, Rihet S, Masure M, Duval-Binniger I, Putaud I, Lorenzato $\mathrm{M}$, Quereux $\mathrm{C}$, Birembaut $\mathrm{P}$ : Comparative analysis of human papilloma virus detection by hybrid capture assay and routine cytologic screening to detect high-grade cervical lesions. Int J Cancer 1998;75: 525-528.

11 Ferris DG, Wright TC Jr, Litaker MS, Richart RM, Lorincz AT, Sun XW, Woodward L: Comparison of two tests for detecting carcinogenic HPV in women with Papanicolaou smear reports of ASCUS and LSIL. J Fam Pract 1998;46:136-141.

12 Sherman ME, Schiffman MH, Lorincz AT, Herrero R, Hutchinson ML, Bratti C, Zahniser D, Morales J, Hildesheim A, Helgesen K, Kelly D, Alfaro M, Mena F, Balmaceda I, Mango L, Greenberg M: Cervical specimens collected in liquid buffer are suitable for both cytologic screening and ancilliary human papillomavirus testing. Cancer 1997;81: 89-97. 
13 Sun XW, Ferenczy A, Johnson D, Koulos JP, Lungu O, Richart RM, Wright JC Jr: Evaluation of the hybrid capture human papillomavirus deoxyribonucleic acid detection test. Am J Obstet Gynecol 1995; 173:1432-1437.

14 Lorincz AT: Hybrid capture method for detection of human papilloma virus DNA in clinical specimens: A tool for clinical management of equivocal Pap smears and for population screening. J Obstet Gynaecol Res 1996;22:629-636.

15 Schneider A, Zahm DM, Kirchmayr $\mathrm{R}$, Schneider VL: Screening for cervical intraepithelial neoplasia grade 2/3: Validity of cytologic study, cervicography and human papillomavirus detection. Am J Obstet Gynecol 1996;174:1534-1541.
16 Rozendaal L, Walboomers JMM, Van Der Linden JC, Voorhorst FJ, Kenemans P, Helmerhorst TJM, Van Ballegooijen M, Meijer CJLM: PCR-based high-risk HPV test in cervical-cancer screening gives objective risk assessment of women with cytomorphologically normal cervical smears. Int J Cancer 1996; 68:766-769.

17 Ho GYF, Burk RD, Klein S, Kadish AS, Chang CJ, Palan P, Basu J, Tachezy R, Lewis R, Romney S: Persistent genital human papillomavirus infection as a risk factor for persistent cervical dysplasia. J Natl Cancer Inst 1995;87:1365-1371.

18 Namkoong SE: Clinical application of HPV typing in cervical cancer. Int J Gynaecol Obstet 1995;49(suppl): S59-S67.

19 Wright TC, Sun XW, Koulos J: Comparison of management algorithms for the evaluation of women with low-grade cytologic abnormalities. Obstet Gynecol 1995;85:202210 .
20 Cox JT, Lorincz AT, Schiffman MH, Sherman ME, Cullen A, Kurman RJ: Human papillomavirus testing by hybrid capture appears to be useful in triaging women with a cytologic diagnosis of atypical squamous cells of undetermined significance. Am J Obstet Gynecol 1995; 172:946-954.

21 Nindle I, Greinke C, Zahm DM, Stockfleth E, Hoyer H, Schneider A: Human papillomavirus distribution in cervical tissues of different morphology as determined by hybrid capture assay and PCR. Int J Gynecol Pathol 1997;16:197-204.

22 Recio FO, Srivastava BIS, Wong C, Hempling RE, Eltabbakh GH, Piver MS: The clinical value of digene hybrid capture HPV DNA testing in a referral-based population with abnormal Pap smears. Eur J Gynaecol Oncol 1998;19:203-208. 